\section{Labial fusion presenting as voiding dysfunction and pseudoincontinence}

Chendrimada Madhu, Ayshini Samarasinghe, Oluseyi Taiye-Akinsun, Harnek Rai

Department of Urogynaecology,

Peterborough City Hospital, UK

\begin{abstract}
Voiding dysfunction secondary to labial fusion is rarely seen in the postmenopausal women. A 68 -year-old female was seen in the outpatient clinic complaining of voiding difficulties and nocturia. Examination showed extensive labial fusion with two small pinhole openings. The patient was treated with surgical division of adhesions followed by estrogen cream.
\end{abstract}

\section{Introduction}

Labial fusion is a condition caused by fibrous adhesions between the labia majora. It is commonly seen in premenarchal girls in the first 2 years of life and post-menopausal women. ${ }^{1-7}$ There appear to be a small number of cases describing the phenomenon in the literature. The etiology is thought to be a chronic irritation followed by inflammation of the vulval skin primarily due to a lack of estrogen. ${ }^{1}$ Other causes include trauma, lichen scleroses, lack of sexual activity, childbirth related trauma and recurrent urinary tract infections.-3

\section{Case Report}

A 68-year-old female was referred for distressing incontinence for 2 years with worsening symptoms in the last 3 months prior to presentation. She reported a constant dribbling, poor and prolonged flow accompanied by a feeling of incomplete emptying of urine. She also suffered from increased frequency of micturition and nocturia. There was no history of stress or urge incontinence. She denied dysuria and history suggestive of urinary tract infections. She was a para 3 and had delivered all her children by spontaneous normal vaginal deliveries. She had a subtotal abdominal hysterectomy and rectocele repair (Fascial repair) in the past. She also had undergone bilateral hip replacements and was sexually not active. Her asthma was under control with regular salbutamol inhaler. Examination showed almost completely fused labia with two small pinhole openings visible. A distended bladder was also noticed. Renal function tests, including a kidneys, ureters and bladder scan were within normal limits.

She was examined under anesthesia, which showed complete labial fusion with two small openings. The opening was opened with sharp and blunt dissection, which further revealed a healthy vagina and the cervix with atrophic changes. Bimanual examination was unremarkable. Her urinary symptoms resolved postoperatively and she was discharged home on local estrogen cream. She was reviewed in six weeks time and was completely asymptomatic.

\section{Discussion}

The majority of cases with labial fusion seem to present with pruritis and discomfort and very rarely with voiding dysfunction and incontinence. ${ }^{4-6}$ In pre-pubertal girls this condition often response to the local application of estrogen creams. However in most menopausal women the sole use of creams have been ineffective and in the majority of cases the condition reoccurrs, surgical intervention seems to be the definitive treatment. ${ }^{7-8}$ Following surgery further precautions such as silicon film and hydrocolloid dressings have been trialed. ${ }^{9}$ Skin flaps from the thigh, which can be tunneled subcutaneously have been used for recurrent fusion with scarring. ${ }^{10}$ Local application of estrogen cream post-operatively has been recommended to prevent recurrence.

\section{References}

1. Muppala H, Meskhi A. Voiding dysfunction due to long-standing labial fusion in an elderly women: a case report. Int Urogynecol J Pelvic Floor Dysfunct 2008;20:251-2.

2. Masaaki T, Yoko K, Yoshiki 0, et al. A case
Correspondence: Chendrimada Madhu, Department of Urogynaecology, Peterborough City Hospital, Peterborough, PE3 9GZ, UK.

E-mail: drmadhuck@gmail.com

Key words: pseudoincontinence, labial fusion, voiding dysfunction, menopause.

Received for publication: 31 August 2011.

Revision received: 21 April 2012.

Accepted for publication: 11 May 2012.

This work is licensed under a Creative Commons Attribution NonCommercial 3.0 License (CC BYNC 3.0).

(C) Copyright C. Madhu et al., 2012

Licensee PAGEPress, Italy

Urogynaecologia 2012; 26:e7

doi:10.4081/uij.2012.e7

of labial adhesion due to lichen sclerosus et atrophicus. Int Urol Nephrol 2004;36:217-8.

3. Dirim A, Hasirci E. Labial fusion causing urinary incontinence and recurrent urinary tract infection in a postmenopausal female: a case report. Int Urogynecol J 2010;22:11920.

4. Julia J, Zacoub M, Levy G. Labial fusion causing urinary incontinence in a female: case report. Int Urogynecol J Pelvic Floor Dysfunct 2003;14:360-1.

5. Pulvino JQ, Flynn MK, Buchsbaum GM. Urinary incontinence secondary to severe labial agglutination. Int Urogynecol J Pelvic Floor Dysfunct 2008;19:245-56.

6. Saito M, Ishida G, Waranabe N, Abe B. Micturitional disturbances due to labial adhesion. Urol J 1998;61:50-1.

7. Parkinson D, Alderman M. Vulval adhesions causing urinary incontinence. Postgrad Med J 1984;60:634-5.

8. Purnell L. W. Unusual cause of urinary obstruction. Br Med J 1969;2:637.

9. Ken'ya F, Iwao N, Hiroya M. Use of moist wound dressings in treatment of labial adhesion in elderly women: a case report. Jpn J Plastic Recons Surg 2005;48:1355-8.

10. Johnson N, Lilford RJ, Sharpe D. A new surgical technique to treat refractory labial fusion in the elderly. Am J Obstet Gynecol 1989;161:289-90. 